\title{
Exploitation of a novel thermo-invariant Multi-Feature Bar for high-precision CMMs and Machine Tools testing
}

\author{
F.VIPREY - H.NOUIRA - S.LAVERNHE - C.TOURNIER
}

the date of receipt and acceptance should be inserted later

\begin{abstract}
A novel thermo-invariant Multi-Feature Bar (MFB) for Machine Tools (MTs) geometric errors' identification has been designed and manufactured. The proposed design of the MFB allows extracting three intrinsic parameters: one linear positioning and two straightness errors. The calibration of the MFB was performed on accurate coordinate measuring machines (CMMs) by applying the reversal technique, in order to separate the geometric errors between the MFB and the CMMs. Furthermore, an intercomparison was conducted between four European National Metrology Institutes (LNE, PTB, CMI, UM) to evaluate the reliability of the proposed calibration methodology and the geometric stability of the proposed material standard with respect to a detailed technical procedure. The collected results show sufficient dimensional stability over time.
\end{abstract}

Keywords Material standard, Calibration, Geometric errors, Intercomparison, Traceability

\section{Introduction}

Coordinate Measuring Machines (CMMs) are widely used in industry for the off-line verification and inspection of workpieces and the calibration of gauges $[1,2$, $3,4,5,6,7,8]$. They allow one to control the workpieces (off-line control) but never to improve the manufacturing process leading to time waste and increasing costs.

F.VIPREY, S.LAVERNHE, C.TOURNIER

LURPA, ENS Cachan, Univ. Paris-Sud, Université ParisSaclay, 94235 Cachan, France

E-mail: fabien.viprey@ens-cachan.fr

\section{H.NOUIRA}

Laboratoire Commun de Métrologie (LNE-CNAM), Laboratoire National de Métrologie et d'Essais (LNE)

1, rue Gaston Boissier, 75724 PARIS Cedex 15, France
Moreover, stationary CMMs may be a part of control systems that give feedback to manufacturing process and are used to stabilize and improve the manufacturing process. They are indeed used in off-line mode but may have positive influence on manufacturing process. However, the inspection of such workpieces in the Machine Tools (MTs) during the manufacturing process (in-process measurement) has become a more and more frequent need in industry. The in-process metrology is almost inaccurate and not traceable due to the volumetric error as specified in the ISO 230-1:2012 [9]. In quasistatic conditions, the volumetric error is defined as a relative deviation between actual and ideal tool and workpiece positionings on MTs. This deviation is essentially generated by quasi-static errors $(70 \%)[9,10,11]$, in particular those caused by the geometric errors: position and orientation errors as well as motion errors. Other sources contributing to the volumetric error are thermal errors and loads [12]. Both the traceability and minimisation of the volumetric error on MTs represent new challenges for researchers involved in National Metrology Institutes (NMIs), manufacturing laboratories and plants. In this context, the EMRP IND62: JRP-TIM (Traceable In-process dimensional Measurement) [13] was launched in 2013, to investigate on-line metrology MTs, including the design and manufacture of highly accurate multi-purpose thermo-invariant material standards, for the mapping of volumetric and task-specific measurement errors.

This paper presents the development of a novel thermoinvariant Multi-Feature Bar (MFB) and the results of the intercomparison organised between four NMIs, all involving in the TIM Project. The aim the intercomparison is to evaluate the reliability of the proposed calibration methodology of the MFB. 
The paper is organised as follows: section 2 depicts the design of the MFB; section 3 presents the calibration procedure of the MFB; section 4 deals with the European participants who perform the intercomparison the collected. An uncertainty budget is also established for each measurement; section 5 presents the determination of the key comparison reference values; finally, a discussion of results is presented in section 6 .

\section{Proposed design for the MFB}

A novel MFB was designed and manufactured as shown in figure 1). Its dimensions are : $80 \mathrm{~mm}$-width $\times 580 \mathrm{~mm}$ long $\times 20 \mathrm{~mm}$-height. It is made of Invar material (FeNi36), certified reference material and considered as thermoinvariant $\left(\alpha / \lambda\right.$ ratio equal to $\left.7.7 \times 10^{-8} \mathrm{~m} . W^{-1}\right)$. This thermal property of the material enables the identification of geometric errors of CMMs and MTs specially located in harsh environment and where the temperature is not controlled.

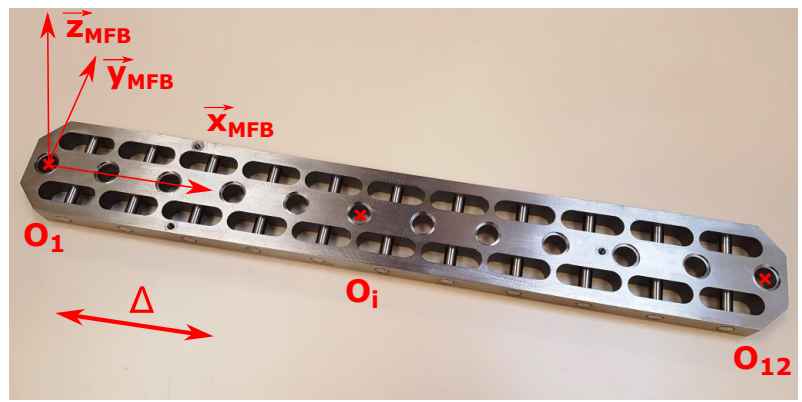

Fig. 1: Picture of the developed Multi-Feature Bar (MFB): a novel thermo-invariant material standard.

The design of the MFB consists of a 3D pattern repeated in the $\Delta$-direction (Figure 1 and 2) [14]. Each pattern contains seven features: four flat surfaces (vertical planes $P L_{L_{j-1}}, P L_{R j-1}, P L_{L_{j}}$ and $\left.P L_{R j}\right)$ and three cylinders (one vertical inner cylinder $H O L_{i}$ and two horizontal outer cylinders $C Y L_{j-1}$ and $C Y L_{j}$ ).

316 coordinate points are expected to be probed in the MFB. The post-processing of the collected measurements allows one to extract 12 points of interest $O_{i}$. The nominal coordinates of the points of interest $O_{i}$ $(1 \leq i \leq 12)$ in the local frame $R_{M F B}$ are defined in equation 1 , with $L=50 \mathrm{~mm}$. The identified points of interest $O_{i}\left(x_{i}, y_{i}, z_{i}\right)$ offer $3 \mathrm{D}$ coordinates in the local frame of the $R_{M F B}$. The real coordinates of the points $O_{i}$ (equation 2) are slightly different from those indicated in the proposed model in equation 1 due to manufacturing errors. Indeed, all of the holes were man-

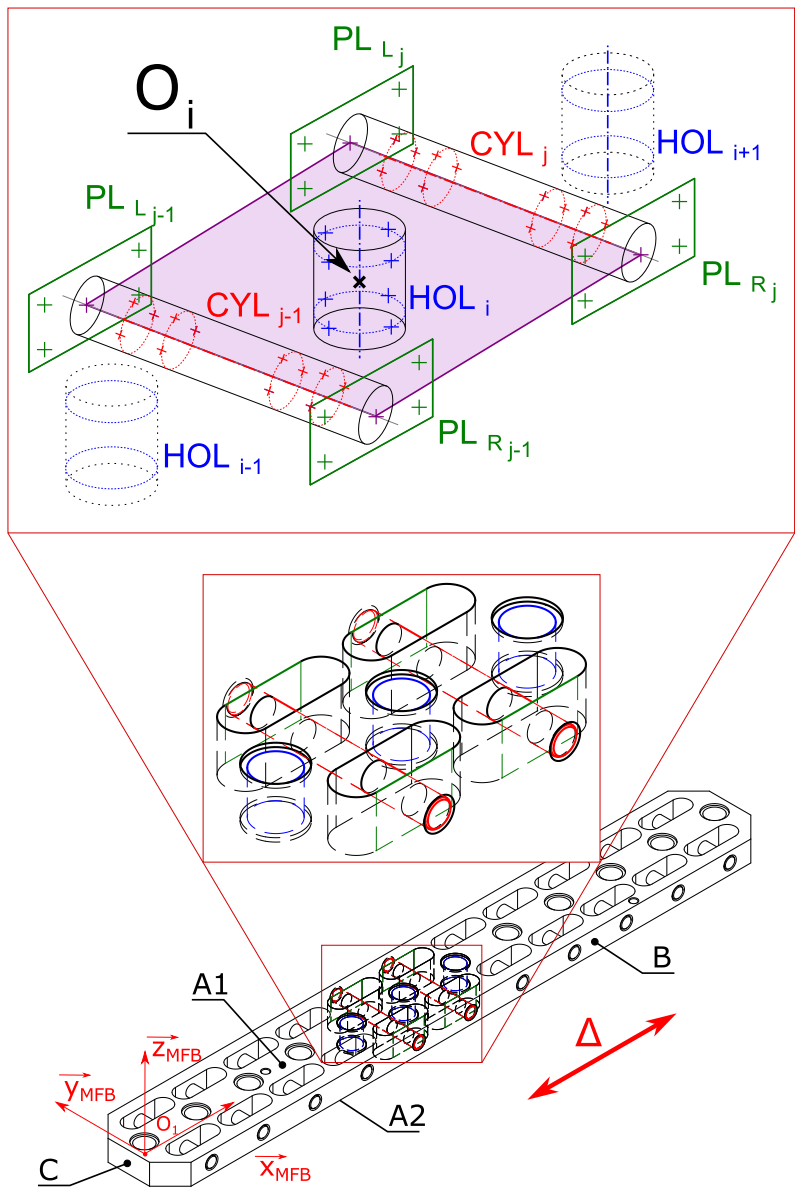

Fig. 2: 3D fundamental pattern of MFB.

ufactured using a wire electrical discharge machining (WEDM). Roughness measurement are performed and the Ra parameters $\left(\lambda_{c}=0.8 \mathrm{~mm}\right)$ are equal to $0.6 \mathrm{~m}$ $0.02 \mathrm{~m}$ and $1.5 \mathrm{~m} \quad 0.02 \mathrm{~m}$ respectively in the wire direction and in transversal direction. Then, the different horizontal rods were machined, carefully ground and glued on the main frame of the MFB. Therefore, a thorough calibration of the MFB is necessary, as described in the following section 3 to extract the intrinsic geometric errors.

$\forall i \in \llbracket 1 ; 12 \rrbracket,\left(\begin{array}{c}x_{i} \\ y_{i} \\ z_{i}\end{array}\right)_{R_{M F B}}=\underbrace{\left(\begin{array}{c}(i-1) \times L \\ 0 \\ 0\end{array}\right)_{R_{M F B}}}_{\text {nominal }}$

$\forall i \in \llbracket 1 ; 12 \rrbracket,\left(\begin{array}{l}x_{i} \\ y_{i} \\ z_{i}\end{array}\right)_{R_{M F B}}=\underbrace{\left(\begin{array}{c}(i-1) \times L \\ 0 \\ 0\end{array}\right)_{R_{M F B}}}_{\text {nominal }}+\underbrace{\left(\begin{array}{c}E_{x x}(i) \\ E_{y x}(i) \\ E_{z x}(i)\end{array}\right) \quad(2)}_{\text {position deviation }}$

The extracted points of interest $O_{i}$ lead to deduce three intrinsic parameters: 
- linear positioning error $E_{x x}$;

- horizontal straightness error $E_{y x}$;

- vertical straightness error $E_{z x}$.

Furthermore, the local frame $R_{M F B}$ is built using the measured data on different surfaces of the patterns [14].

\section{Calibration Procedure}

Calibration of the MFB was carried out on a traceable high-precision CMM by applying reversal in the metrology room, when the temperature an humidity are controlled. The reversal technique [15] was applied in order to separate the motion errors of the used accurate CMM from the geometric errors of the MFB. This technique concerns only the straightnesses and never the positioning errors, but the absolute length between each hole can be corrected by a substitution technique [6].

The motion errors of CMM contain both systematic component $\left(E_{C M M}\right)$ and random component $\left(\epsilon_{C M M}\right)$. The application of the reversal technique enables to determine the systematic components. The random is still combined with the geometric errors of the MFB, the measurements are repeated many times to average out the random effects.

To apply of the reversal technique, the MFB was carefully aligned along the high-precision CMM axis with the smallest linear positioning error (figure 9) that was identified by previous calibration.

The principle of the reversal technique is illustrated in figure 3 , where $M_{x}, M_{y}$ and $M_{z}$ are the component of measurement along $x_{M F B}, y_{M F B}$, and $z_{M F B}$ of $R_{M F B}$. $E_{y x}$, and $E_{z x}$ are the straightnesses of the MFB along $y_{M F B}$ and $z_{M F B}$ in $R_{M F B}$. Moreover, the superscripts $N R$ and $R$ refer to the position of the MFB: "No Reversal" or "Reversal". Whatever the considered straightness of the MFB, $E_{M F B}^{N R}$ is equal to $-E_{M F B}^{R}$ in the MFB coordinate system. According to the figure 4, the relations between the measurement and the straightnesses of the CMM and the MFB, before and after reversal, can be expressed by the equation 3 . The term $\epsilon_{Y X_{C M M}}$ depicts the zero mean random error of the CMM in the direction $\mathrm{Y}$ along $\mathrm{X}$-axis in machine coordinate system.

$$
\left\{\begin{array}{l}
E_{y x}(i)=M_{y}^{N R}(i)+E_{Y X_{C M M}}(i)+\epsilon_{Y X_{C M M}}(i) \\
-E_{y x}(i)=M_{y}^{R}(i)+E_{Y X_{C M M}}(i)+\epsilon_{Y X_{C M M}}(i)
\end{array}\right.
$$

The geometric errors can be calculated with respect to equation 4.

$$
\left\{\begin{array}{l}
E_{y x}(i)=\frac{1}{2}\left[M_{y}^{N R}(i)-M_{y}^{R}(i)\right]+\epsilon_{Y X_{C M M}}(i) \\
E_{z x}(i)=\frac{1}{2}\left[M_{z}^{N R}(i)-M_{z}^{R}(i)\right]+\epsilon_{Z X_{C M M}}(i)
\end{array}\right.
$$

The zero mean random errors $\epsilon_{Y X_{C M M}}$ and $\epsilon_{Z X_{C M M}}$ cannot be subtracted directly because they are algebraic values, but averaging over repeated measurements will average the random terms toward zero.

The linear positioning error $E_{x x_{M F B}}$ of the MFB was calculated by using equation 5 . Since the linear positioning error $E_{X X_{C M M}}$ of the CMM cannot be deduced by reversal technique (figure 5) and it was compensated.

$$
E_{x x}(i)=\frac{1}{2}\left[M_{X}^{N R}(i)+M_{X}^{R}(i)\right]+E_{X X_{C M M}}(i)+\epsilon_{X X_{C M M}}(i)
$$

The calibration tests were repeated five times to reduce the random errors and also to investigate the measurement repeatability with respect to the VIM [16]. Furthermore, specified reproducibility condition of measurement in [16] is a set of conditions including different locations, operators, measuring systems, and replicate measurements of the same or similar objects. To evaluate the reliability of the proposed calibration methodology and the geometry stability of the MFB, an intercomparison was organised between four NMIs. The calibration steps are summarised in figure 6 . These steps were repeated $n=5$ times per participant. The procedure is divided into two parts. On the one hand, the steps undertaken by all the participants. The detailed technical procedure is in agreement with [17] and includes handling precautions, devices description, use of the modular inspection system to build the work holder of the MFB, specifications for the tightening and cleaning operations (to be carried out before measurement), parameters of touch probe and CMM, calibration steps, CMM programmes to perform measurements, instructions to report the results of measurements and instructions to report the calibration feedback.

Each participant received the MFB, the associated clamping parts as well as all the necessary devices. On the other hand, the steps undertaken by LNE where the analysis of collected data was carried out using a specific algorithm developed for these tasks.

\section{Intercomparison}

\subsection{Participants}

The intercomparison was jointly organised by the following four participants: 


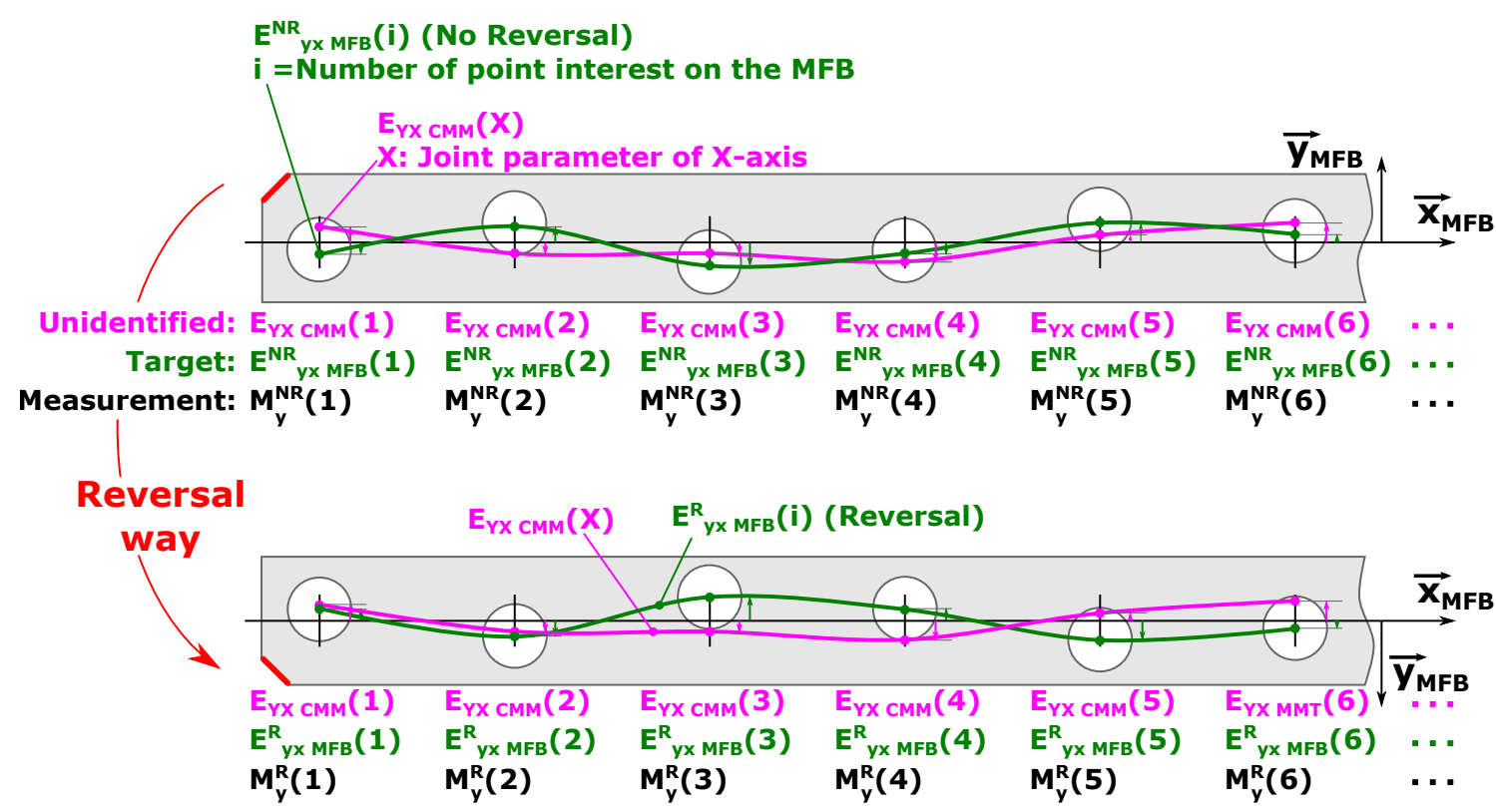

Fig. 3: Reversal technique for straightness error $E_{Y X}$ of MFB aligned along X-axis of CMM.
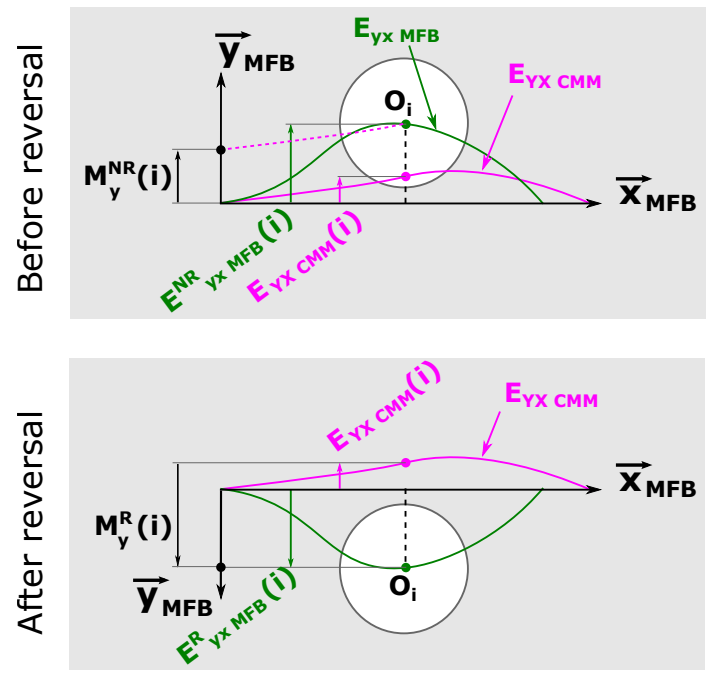

Fig. 4: Effect of the reversal technique on the straightness error - Zoom on a point of interest $O_{i}$ of the MFB.

- Ceský Metrologický Institut (Czech Republic);

- Physikalisch-Technische Bundesanstalt (Germany);

- Univerza v Mariboru (Slovenia);

- Laboratoire National de Métrologie et d'Essais (France).

Details about the used CMMs are listed in table 1 including the reproducibility conditions [16] such as the measuring systems and the environment conditions. Each experiment is displayed in figure 7 .

\subsection{Collected Results}

First and last calibration tests were performed at LNE and took place seven months apart.

In figure $8 \mathrm{a}$, linear positioning error of the MFB $E_{x x}^{L N E}$ can reach a maximal value of $-41.8 \mu \mathrm{m}$ (last point of interest named $O_{12}$ ). The results reflect the impact of the entire error introduced by the MFB manufacturing process. Calibration tests were repeated five times and the results are presented in figure 8a. The calculated standard deviation can reach $1.0 \mu \mathrm{m}$ for the point of interest $O_{10}$.

Straightness errors were defined on end-points Reference Straight Line (RSL) [9], applied on both $O_{1}$ and $O_{12}$ (Figure 1). Based on the definitions of end-points RSLs where the straightness errors $E_{y x}^{L N E}$ and $E_{z x}^{L N E}$ are referred, the values of estimated standard deviations for $O_{1}$ and $O_{12}$ are equal to zero. Besides, the straightness errors reflect both the geometry errors of the manufacturing process and the assembly of the different horizontal rods carefully glued on the main frame of the MFB. The maximal values of horizontal and vertical straightness errors $\left(E_{y x}^{L N E}\right.$, and $\left.E_{z x}^{L N E}\right)$ are $-11.5 \mu \mathrm{m}$ and $20.3 \mu \mathrm{m}$. The maximal values of estimated standard deviations are $s_{E_{y x}^{L N E}}=0.7 \mu \mathrm{m}$ and $s_{E_{z x}^{L N E}}=1.7 \mu \mathrm{m}$ respectively for the points of interest $O_{11}$ and $O_{5}$.

Figure 9 summarizes the identified geometric errors by all participants. Each measured value is associated with its estimated standard deviation. Deviations can be observed especially for linear position- 

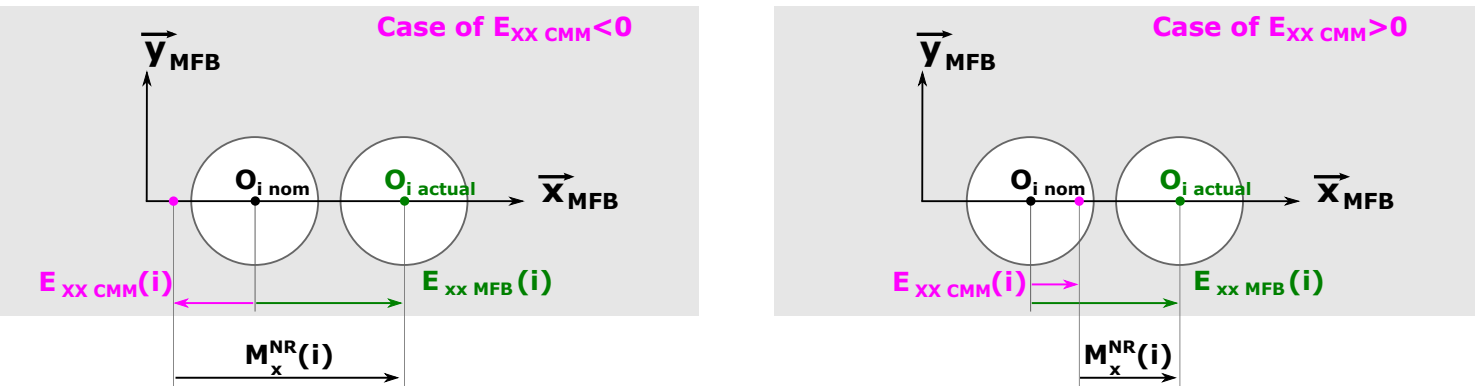

Fig. 5: Effect of the reversal technique on the linear positioning error - Zoom on a point of interest $O_{i}$ of the MFB.

Table 1: Intercomparison: details of reproducibility condition.

\begin{tabular}{cccccc}
\hline Participant & $\begin{array}{c}\text { CMM } \\
\text { type }\end{array}$ & $\begin{array}{c}\text { CMM } \\
\text { size }\end{array}$ & $\begin{array}{c}\text { Maximal } \\
\text { Permitted Error (MPE) }\end{array}$ & $\begin{array}{c}\text { Room } \\
\text { temperature }\end{array}$ & $\begin{array}{c}\text { Alignment } \\
\text { axis }\end{array}$ \\
\hline Name & Name & $\mathrm{cm}^{3}$ & $E(\mu \mathrm{m})+L(\mathrm{~m}) \times F(\mu \mathrm{m} / \mathrm{m})$ & ${ }^{\circ} \mathrm{C}$ \\
\hline \hline LNE & Renault Automotion 251310 & $250 \times 130 \times 100$ & $4.5+L \times 4.0$ & $20,26 \pm 0,03$ \\
\hline CMI & SIP CMM5 & $71 \times 71 \times 55$ & $0.8+L \times 1.3$ & $19,73 \pm 0,09$ \\
\hline UM & Zeiss UMC 850 & $120 \times 85 \times 60$ & $2.1+L \times 3.3$ & $20,39 \pm 0,03$ \\
\hline PTB & Zeiss UPMC 850 CARAT & $85 \times 120 \times 60$ & $0.8+L \times 3.5$ & $20,18 \pm 0,04$ \\
\hline LNE & Renault Automotion 251310 & $250 \times 130 \times 100$ & & Y \\
\hline
\end{tabular}

ing error $E_{x x}$ and vertical straightness error $E_{z x}$. The maximal value of these deviations is equal to $5.5 \mu \mathrm{m}$, $1.2 \mu \mathrm{m}$ and $2.9 \mu \mathrm{m}$, respectively for $E_{x x}\left(O_{10}\right), E_{x x}\left(O_{5}\right)$ and $E_{z x}\left(O_{7}\right)$.

Deviations of straightness errors can be reduced if further criterion are selected for RSL. Therefore, the mean minimum zone RSL parameters are usually used to evaluate the minimum straightness error. The minimum standard deviations are determined using least squares RSL. Since software for minimum zone calculation has a limited availability, straightness error is evaluated as the minimum error resulting from the least squares RSL or using the end-point RSL $[9,18]$. The end-points seem to be more suitable for the MFB calibration and could be physically defined by measurement.

\subsection{Uncertainty of Measurement}

The uncertainty of measurement was estimated according to [19].

The following conditions apply:

- the CMM is within the manufacturer's specification $(E+L \times F)$

- after the compensation of temperature gap between $20^{\circ} \mathrm{C}$ and the metrology room temperature (table 1 ), the temperature is equal to $20^{\circ} \mathrm{C} \pm \Delta_{l a b}{ }^{\circ} \mathrm{C}$ (where $\Delta_{l a b}$ is described in table 1 and correspond to the standard deviation of room temperature during the measurements).
Regarding the table 1 , the temperature fluctuations of the metrology rooms which could be represented by arcsine distributions, are very small (maximal value $\left.\leq 0.09^{\circ}\right)$. The temperatures of the MFB and the CMMs during measurements have to be considered with more fluctuations due to handling conditions, friction, and thermal radiation or convection. Thus, the following assumptions apply:

- the temperature of the CMM is equal to $20^{\circ} \mathrm{C} \pm{ }^{\circ} \mathrm{C}$ (uniform distribution),

- due to handling conditions and MFB temperature stabilising, the mean temperature deviation between the $\mathrm{CMM}$ and the $\mathrm{MFB}$ is equal to $0^{\circ} \mathrm{C} \pm 1^{\circ} \mathrm{C}$ (uniform distribution),

- mean deviation between the temperature of the MFB or the CMM and the room metrology after compensation $\left(20^{\circ} \mathrm{C}\right)$ is equal to zero,

- in the worst-case the CMMs are made of steel $(\alpha=$ $\left.12 \mu m . m^{-1} \cdot C^{-1}\right)$,

- the values of the coefficient of thermal expansion $(\alpha)$ are equal to the nominal value $\alpha_{C M M}=12 \mu \mathrm{m} . \mathrm{m}^{-1} . C^{-1}$ (steel) and $\alpha_{M F B}=12 \mu m \cdot m^{-1} \cdot C^{-1}$ (Invar) and the associated standard deviations are $1 \mu \mathrm{m} . \mathrm{m}^{-1} . C^{-1}$ (Gaussian distribution).

The main components (contribution $>1 \%$ ) of the combined standard uncertainty $u_{c}$ are:

- repeatability tests with $n=5\left(u_{r e p}\right)$;

- CMM (standard uncertainty $u_{C M M}$ );

- temperature drift between CMM and MFB $\left(u_{T_{1}}\right)$. 


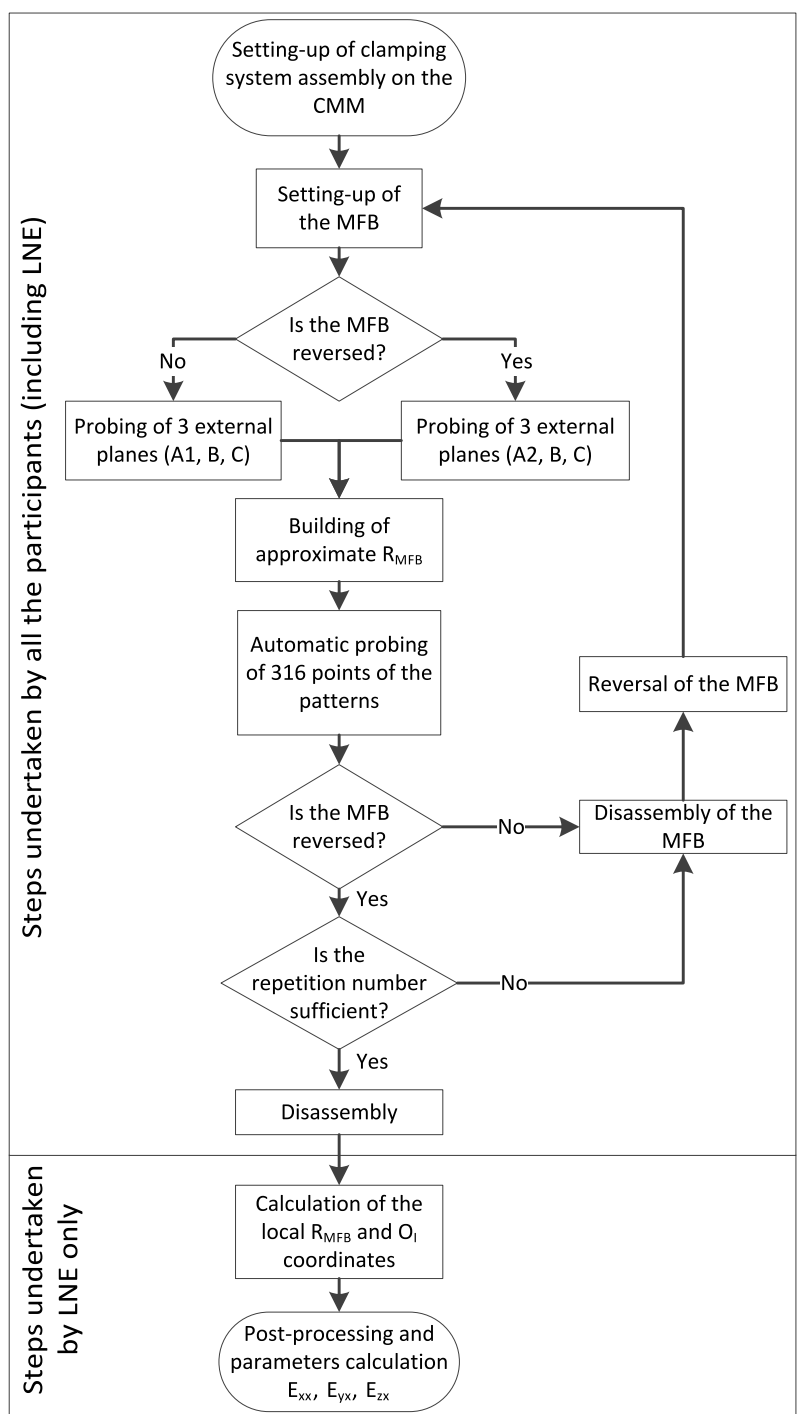

Fig. 6: Flowchart of the calibration steps.

An uncertainty budget is given in table 2 with respect to [19]. The combined variance $u_{c}^{2}(\beta)$ can be considered as the sum of terms depicted in equation 6. Each parameter of the estimated variance associated with the output estimate $\beta$ (i.e. $\beta$ can be $E_{x x}\left(O_{i}\right), E_{y x}\left(O_{i}\right)$ or $\left.E_{z x}\left(O_{i}\right)\right)$ generated by the estimated variance $\left(C_{i} u_{i}\right)^{2}$.

$u_{c}^{2}(\beta)=\sum_{i=1}^{3} C_{i}{ }^{2} u_{i}{ }^{2}=u_{r e p}^{2}+u_{C M M}^{2}+u_{T_{1}}^{2}$

Based on the numerical values given in table 1 , table 2 and measurement results, the combined standard uncertainty $\left(u_{c}\right)$ for geometric errors $E_{x x}\left(O_{i}\right), E_{y x}\left(O_{i}\right)$ and $E_{z x}\left(O_{i}\right)$ were estimated and depicted in table 3 . The level and maximum values of combined standard uncertainties depend especially of the CMM's uncer- tainty component $u_{C M M}$.

The expanded uncertainties $U$ for each point of interest $O_{i}$ are obtained by multiplying the combined standard uncertainties $u_{c}$ by the coverage factor $k=2$ [19].

\section{Determination of Reference Values}

\subsection{Evaluation of Key Comparison Reference Values (KCRVs)}

To guarantee the internal consistency of the comparison measurements:

- each participant provides the measured dataset and the associated standard uncertainty;

- each participant's measurement is carried out independently;

- the Gaussian distribution was assigned to each measurement.

Under these circumstances, the Procedure $A$ proposed in [21] based on the use of least-square adjustment was applied to evaluate the KCRVs. The weighted mean values of participants' measurements, $\bar{E}_{x x}, \bar{E}_{y x}$ and $\bar{E}_{z x}$ (equation 7) for each point of interest $O_{i}$, were determined using the inverses of squares of the associated standard uncertainties as weight parameters. The associated standard deviations are defined in equation 8 .

$\forall i \in \llbracket 1 ; 12 \rrbracket, j \in\{\mathbf{L N E}, \mathrm{CMI}, \mathrm{UM}, \mathbf{P T B}, \mathbf{L N E}\}$

$$
\left\{\begin{array}{l}
\bar{E}_{x x}\left(O_{i}\right)=\frac{\sum_{j} E_{x x}^{j}\left(O_{i}\right) \times u_{c_{j}}^{-2}\left(E_{x x}^{j}\left(O_{i}\right)\right)}{\sum_{j} u_{c_{j}}^{-2}\left(E_{x x}^{j}\left(O_{i}\right)\right)} \\
\bar{E}_{y x}\left(O_{i}\right)=\frac{\sum_{j} E_{y x}^{j}\left(O_{i}\right) \times u_{c_{j}}^{-2}\left(E_{y x}^{j}\left(O_{i}\right)\right)}{\sum_{j} u_{c_{j}}^{-2}\left(E_{y x}^{j}\left(O_{i}\right)\right)} \\
\bar{E}_{z x}\left(O_{i}\right)=\frac{\sum_{j} E_{z x}^{j}\left(O_{i}\right) \times u_{c_{j}}^{-2}\left(E_{z x}^{j}\left(O_{i}\right)\right)}{\sum_{j} u_{c_{j}}^{-2}\left(E_{z x}^{j}\left(O_{i}\right)\right)}
\end{array}\right.
$$

$\forall i \in \llbracket 1 ; 12 \rrbracket, j \in\{\mathbf{L N E}, \mathrm{CMI}, \mathrm{UM}, \mathbf{P T B}, \mathbf{L N E}\}$

$$
\left\{\begin{array}{l}
u\left(\bar{E}_{x x}\left(O_{i}\right)\right)=\left(\sum_{j} u_{c_{j}}^{-2}\left(E_{x x}^{j}\left(O_{i}\right)\right)\right)^{-\frac{1}{2}} \\
u\left(\bar{E}_{y x}\left(O_{i}\right)\right)=\left(\sum_{j} u_{c_{j}}^{-2}\left(E_{y x}^{j}\left(O_{i}\right)\right)\right)^{-\frac{1}{2}} \\
u\left(\bar{E}_{z x}\left(O_{i}\right)\right)=\left(\sum_{j} u_{c_{j}}^{-2}\left(E_{z x}^{j}\left(O_{i}\right)\right)\right)^{-\frac{1}{2}}
\end{array}\right.
$$

Since the Chi-square goodness-of-fit test does not reject the null hypothesis at the $5 \%$ significance level [21], 


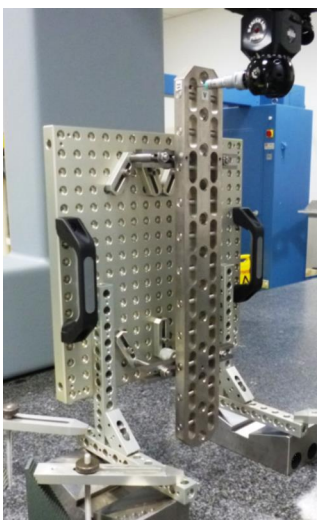

LNE

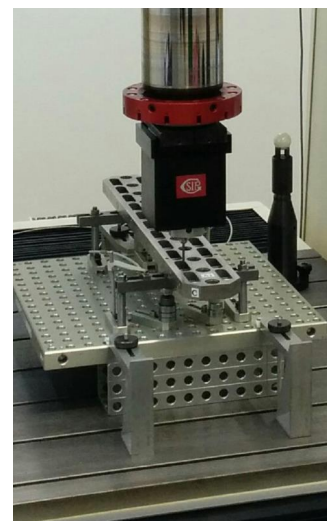

CMI

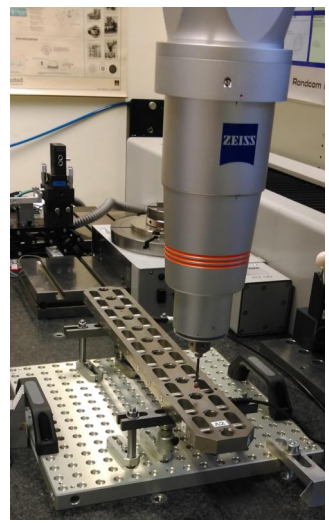

UM

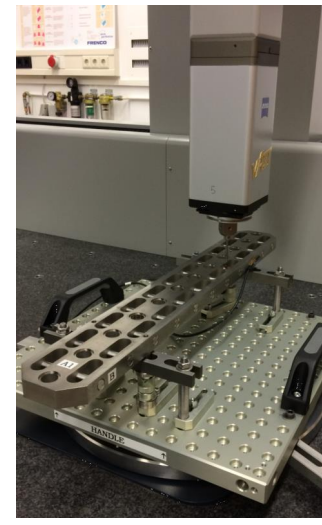

РTB

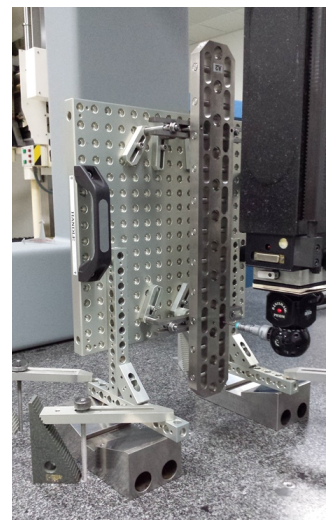

LNE

Fig. 7: Illustration of the MFB and work holder assembly during calibration on CMM.

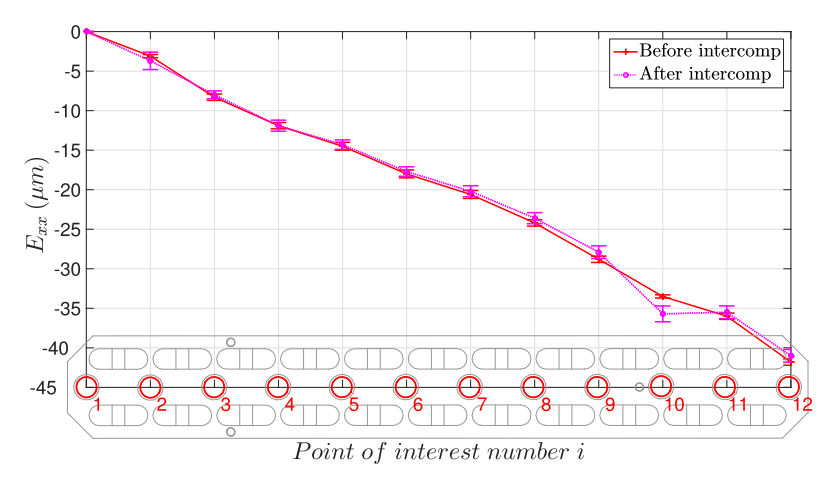

(a) Linear positioning error $E_{x x}^{L N E}\left(O_{i}\right)$.
$\begin{array}{lllllllllllll}\mathrm{O}_{1} & \mathrm{O}_{2} & \mathrm{O}_{3} & \mathrm{O}_{4} & \mathrm{O}_{5} & \mathrm{O}_{6} & \mathrm{O}_{7} & \mathrm{O}_{8} & \mathrm{O}_{9} & \mathrm{O}_{10} & \mathrm{O}_{11} & \mathrm{O}_{12}\end{array}$ 25 IIO

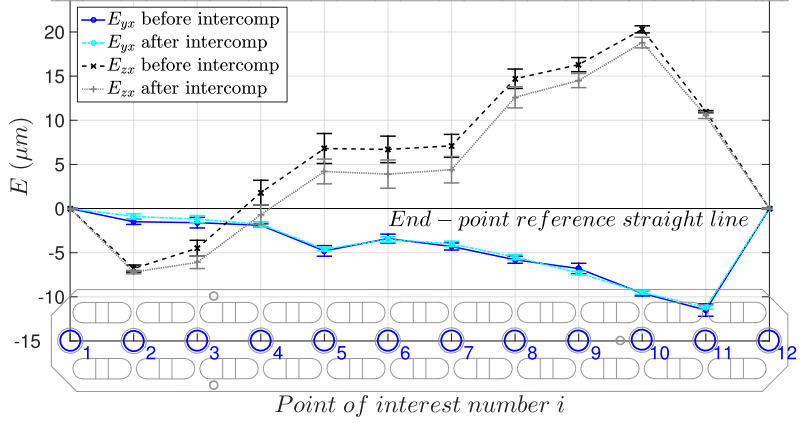

(b) Horizontal straightness error $E_{y x}^{L N E}\left(O_{i}\right)$ and vertical straightness error $E_{x x}^{L N E}\left(O_{i}\right)$.

Fig. 8: LNE's calibration results before and after intercomparison of each point of interest $O_{i}$ of the MFB.

Table 2: Detailed uncertainty budget.

\begin{tabular}{|c|c|c|c|c|c|c|c|}
\hline i & $\begin{array}{l}\text { Component } \\
\text { name }\end{array}$ & $\begin{array}{c}\text { Evaluation } \\
\text { type }\end{array}$ & $\begin{array}{c}\text { Half } \\
\text { width }\end{array}$ & $\begin{array}{c}\text { Distribution } \\
\text { type }\end{array}$ & $\begin{array}{c}\text { Standard } \\
\text { uncertainty }\end{array}$ & $\begin{array}{c}\text { Sensivity } \\
\text { coefficient }\left(C_{i}\right)\end{array}$ & $\begin{array}{c}\text { Uncertainty } \\
\text { component }\left(C_{i} u_{i}\right)\end{array}$ \\
\hline 1 & $u_{r e p}$ & $\mathrm{~A}$ & - & Student & $s_{E_{i x}} \mu m$ & $\sqrt{3}^{*}$ & $\sqrt{3} \times s_{E_{i x}} \mu m$ \\
\hline \multirow[b]{2}{*}{2} & \multirow[b]{2}{*}{$u_{C M M}$} & \multirow[b]{2}{*}{ B } & - & $\mathrm{k}=2^{* *}$ & $E / 2 \mu m$ & 1 & $E / 2 \mu m$ \\
\hline & & & - & $\mathrm{k}=2$ & $F / 2 \mu m \cdot m^{-1}$ & $\mathrm{~L}^{* * *}$ & $L \times F / 2 \mu m$ \\
\hline 3 & $u_{T_{1}}$ & B & $1^{\circ} \mathrm{C}$ & Uniform & $\frac{1}{\sqrt{(3)}}^{\circ} C$ & $L \times \alpha_{M F B}$ & $0.58 \times L \mu m$ \\
\hline
\end{tabular}

the calculated weight means in equation 7 and associated standard deviation in equation 8 are accepted as KCRVs with associated standard uncertainties. Henceforth the KCRVs and associated standard uncertainties are $E_{x x}^{r e f}\left(O_{i}\right), E_{y x}^{r e f}\left(O_{i}\right), E_{z x}^{r e f}\left(O_{i}\right)$ and $u\left(E_{x x}^{r e f}\left(O_{i}\right)\right)$, $u\left(E_{y x}^{r e f}\left(O_{i}\right)\right)$ and $u\left(E_{z x}^{r e f}\left(O_{i}\right)\right)$, respectively (Table 4$)$.
Based on the results presented in table 4, the KCRVs of linear positioning error of the MFB reach a maximal value of $-39.3 \mu \mathrm{m}$. The horizontal and vertical straightness KCRVs reach $-11.1 \mu \mathrm{m}$ and $18.8 \mu \mathrm{m}$, respectively. Since all collected values are considered for the calculation of KCRVs and associated standard uncertainties, 
Table 3: Estimation of the combined standard uncertainty results of $E_{x x}\left(O_{i}\right), E_{y x}\left(O_{i}\right)$ and $E_{z x}\left(O_{i}\right)$ for all participants and all point of interest.

\begin{tabular}{c|ccccc|cccccc|ccccc}
\hline$O_{i}$ & \multicolumn{4}{|c|}{$u_{c_{j}}\left(E_{x x}^{j}\left(O_{i}\right)\right)(\mu m)$} & \multicolumn{4}{c|}{$u_{c_{j}}\left(E_{y x}^{j}\left(O_{i}\right)\right)(\mu m)$} & \multicolumn{4}{c}{$u_{c_{j}}\left(E_{z x}^{j}\left(O_{i}\right)\right)(\mu m)$} \\
\hline $\mathbf{i}$ & LNE & CMI & UM & PTB & LNE & \multicolumn{2}{c|}{ LNE } & CMI & UM & PTB & LNE & LNE & CMI & UM & PTB & LNE \\
\hline 1 & 2.3 & 0.4 & 1.1 & 0.4 & 2.3 & 2.3 & 0.4 & 1.1 & 0.4 & 2.3 & 2.3 & 0.4 & 1.1 & 0.4 & 2.3 \\
2 & 2.3 & 0.4 & 1.5 & 0.6 & $\mathbf{3 . 0}$ & 2.3 & $\mathbf{0 . 7}$ & $\mathbf{1 . 4}$ & 0.5 & 2.3 & 2.3 & 0.6 & 1.1 & 0.7 & 2.3 \\
3 & 2.4 & 0.5 & 1.9 & 0.6 & 2.5 & $\mathbf{2 . 5}$ & 0.4 & $\mathbf{1 . 4}$ & 0.5 & $\mathbf{2 . 4}$ & 2.8 & 1.2 & 1.8 & 1.5 & 2.5 \\
4 & 2.4 & 0.5 & 1.8 & 0.6 & 2.6 & 2.3 & 0.5 & 1.3 & 0.5 & 2.3 & 3.3 & 1.8 & 2.5 & 2.1 & 2.9 \\
5 & 2.4 & 0.6 & 1.8 & 0.6 & 2.5 & $\mathbf{2 . 5}$ & 0.5 & $\mathbf{1 . 4}$ & 0.5 & 2.3 & $\mathbf{3 . 7}$ & $\mathbf{2 . 1}$ & 2.8 & 2.6 & 3.3 \\
6 & 2.5 & 0.6 & 2.2 & 0.6 & 2.5 & 2.4 & 0.5 & 1.1 & $\mathbf{0 . 6}$ & 2.3 & 3.5 & $\mathbf{2 . 1}$ & 3.1 & $\mathbf{2 . 9}$ & $\mathbf{3 . 5}$ \\
7 & 2.5 & 0.6 & 2.1 & 0.7 & 2.6 & 2.3 & 0.5 & 1.1 & 0.5 & 2.3 & 3.1 & 2.0 & $\mathbf{3 . 3}$ & $\mathbf{2 . 9}$ & 3.4 \\
8 & 2.5 & 0.6 & 1.9 & 0.8 & 2.7 & 2.3 & 0.6 & 1.1 & 0.5 & 2.3 & 2.9 & 1.7 & 2.9 & 2.7 & 3.0 \\
9 & 2.5 & 0.7 & 1.9 & 0.9 & 2.7 & $\mathbf{2 . 5}$ & 0.5 & 1.2 & 0.4 & 2.3 & 2.7 & 1.2 & 2.3 & 2.1 & 2.7 \\
10 & 2.5 & 0.7 & 1.9 & 1.0 & $\mathbf{3 . 0}$ & 2.3 & 0.5 & 1.1 & 0.5 & 2.3 & 2.4 & 1.1 & 1.8 & 1.4 & 2.5 \\
11 & $\mathbf{2 . 6}$ & 0.7 & 2.1 & 1.0 & 2.9 & $\mathbf{2 . 5}$ & 0.4 & 1.1 & 0.4 & 2.3 & 2.3 & 0.6 & 1.2 & 0.6 & 2.3 \\
12 & $\mathbf{2 . 6}$ & $\mathbf{0 . 8}$ & $\mathbf{2 . 5}$ & $\mathbf{1 . 1}$ & 2.9 & 2.3 & 0.4 & 1.1 & 0.4 & 2.3 & 2.3 & 0.4 & 1.1 & 0.4 & 2.3 \\
\hline
\end{tabular}

these values are slightly different from those obtained for the case of LNE. The deviation between these values and the LNE's values is due to the consideration of all the collected values and their associated standard uncertainties. Therefore, the reference values and associated standard uncertainties reflect the impact of the reproducibility of the calibration process. The distribution of the standard uncertainty $u\left(E_{z x}^{r e f}\left(O_{i}\right)\right)$ is centred, symmetrically arranged and the maximum value is reached at $O_{6}$ and is equal to $1.3 \mu \mathrm{m}$ (Figure 10).

Table 4: Key comparison reference values of the MFB.

\begin{tabular}{ccc|cc|cc} 
& \multicolumn{2}{c|}{$E_{x x}^{r e f}\left(O_{i}\right)$} & \multicolumn{2}{c|}{$E_{y x}^{r e f}\left(O_{i}\right)$} & \multicolumn{2}{c}{$E_{z x}^{r e f}\left(O_{i}\right)$} \\
\hline \multirow{2}{*}{$O_{i}$} & values & $\mathbf{u}$ & values & $\mathbf{u}$ & values & $\mathbf{u}$ \\
\cline { 2 - 7 } & $\mu m$ & $\mu m$ & $\mu m$ & $\mu m$ & $\mu m$ & $\mu m$ \\
\hline 1 & 0,0 & 0,3 & 0,0 & 0,3 & 0,0 & 0,3 \\
2 & $-2,8$ & 0,3 & $-1,4$ & $\mathbf{0 , 4}$ & $-7,0$ & 0,4 \\
3 & $-7,4$ & 0,3 & $-1,4$ & 0,3 & $-5,6$ & 0,8 \\
4 & $-11,1$ & 0,4 & $-1,9$ & 0,3 & 0,1 & 1,1 \\
5 & $-13,0$ & 0,4 & $-5,0$ & 0,3 & 5,0 & 1,2 \\
6 & $-16,6$ & 0,4 & $-3,6$ & 0,3 & 4,6 & $\mathbf{1 , 3}$ \\
7 & $-19,6$ & 0,4 & $-4,1$ & 0,3 & 5,0 & 1,2 \\
8 & $-22,5$ & 0,5 & $-5,5$ & 0,3 & 13,0 & 1,1 \\
9 & $-25,3$ & 0,5 & $-7,5$ & 0,3 & 14,7 & 0,9 \\
10 & $-32,1$ & 0,5 & $-9,2$ & 0,3 & $\mathbf{1 8 , 8}$ & 0,7 \\
11 & $-34,4$ & $\mathbf{0 , 6}$ & $\mathbf{- 1 1 , 1}$ & 0,3 & 10,3 & 0,4 \\
12 & $\mathbf{- 3 9 , 3}$ & $\mathbf{0 , 6}$ & 0,0 & 0,3 & 0,0 & 0,3 \\
\hline
\end{tabular}

\subsection{Degrees of Equivalence}

The degree of equivalence can be of two different types. The first type is the degree of equivalence of participant $j(j \in\{L N E, C M I, U M, P T B, L N E\})$ from the reference value. It is characterised by the deviation $d^{j}=$ $\left(d_{x x}^{j}, d_{y x}^{j}, d_{z x}^{j}\right)^{T}$ and the expanded uncertainties $U\left(d^{j}\right)=$
$\left(U\left(d_{x x}^{j}\right), U\left(d_{y x}^{j}\right), U\left(d_{z x}^{j}\right)\right)^{T}$ given in equation 9 and 10.

$\forall i \in \llbracket 1 ; 12 \rrbracket, j \in\{\mathbf{L N E}, \mathrm{CMI}, \mathrm{UM}, \mathbf{P T B}, \mathbf{L N E}\}$

$$
\left\{\begin{array}{l}
d_{x x}^{j}=E_{x x}^{j}\left(O_{i}\right)-E_{x x}^{r e f}\left(O_{i}\right) \\
d_{y x}^{j}=E_{y x}^{j}\left(O_{i}\right)-E_{y x}^{r e f}\left(O_{i}\right)(9) \\
d_{z x}^{j}=E_{z x}^{j}\left(O_{i}\right)-E_{z x}^{r e f}\left(O_{i}\right)
\end{array}\right.
$$

$\forall i \in \llbracket 1 ; 12 \rrbracket, j \in\{\mathbf{L N E}, \mathrm{CMI}, \mathrm{UM}, \mathbf{P T B}, \mathbf{L N E}\}$

$$
\left\{\begin{array}{l}
U\left(d_{x x}^{j}\right)=k\left(u^{2}\left(E_{x x}^{j}\left(O_{i}\right)\right)-u^{2}\left(E_{x x}^{r e f}\left(O_{i}\right)\right)\right)^{\frac{1}{2}} \\
U\left(d_{y x}^{j}\right)=k\left(u^{2}\left(E_{y x}^{j}\left(O_{i}\right)\right)-u^{2}\left(E_{y x}^{r e f}\left(O_{i}\right)\right)\right)^{\frac{1}{2}} \\
U\left(d_{z x}^{j}\right)=k\left(u^{2}\left(E_{z x}^{j}\left(O_{i}\right)\right)-u^{2}\left(E_{z x}^{r e f}\left(O_{i}\right)\right)\right)^{\frac{1}{2}}
\end{array}\right.
$$

The degrees of equivalence are illustrated in figure 11. The selected coverage factor $k$ for the expanded uncertainty is equal to 2, leading to a confidence level of 95\% [19]. The attribution of a large CMM uncertainty causes the increase of expanded uncertainties.

The second type of degree of equivalence was calculated between participants $j$ and $k(k \neq j)$ characterised by the deviations and the expanded uncertainties: $d^{j, k}=\left(d_{x x}^{j, k}, d_{y x}^{j, k}, d_{z x}^{j, k}\right)^{T}$ and $U\left(d^{j, k}\right)=\left(U\left(d_{x x}^{j, k}\right)\right.$, $\left.U\left(d_{y x}^{j, k}\right), U\left(d_{z x}^{j, k}\right)\right)^{T}$ respectively (equation 11 and 12 ).

$\forall i \in \llbracket 1 ; 12 \rrbracket, j \in\{\mathbf{L N E}, \mathrm{CMI}, \mathrm{UM}, \mathbf{P T B}, \mathbf{L N E}\}$

$$
\left\{\begin{array}{l}
d_{x x}^{j, k}=E_{x x}^{j}\left(O_{i}\right)-E_{x x}^{k}\left(O_{i}\right) \\
d_{y x}^{j, k}=E_{y x}^{j}\left(O_{i}\right)-E_{y x}^{k}\left(O_{i}\right)(11) \\
d_{z x}^{j, k}=E_{z x}^{j}\left(O_{i}\right)-E_{z x}^{k}\left(O_{i}\right)
\end{array}\right.
$$




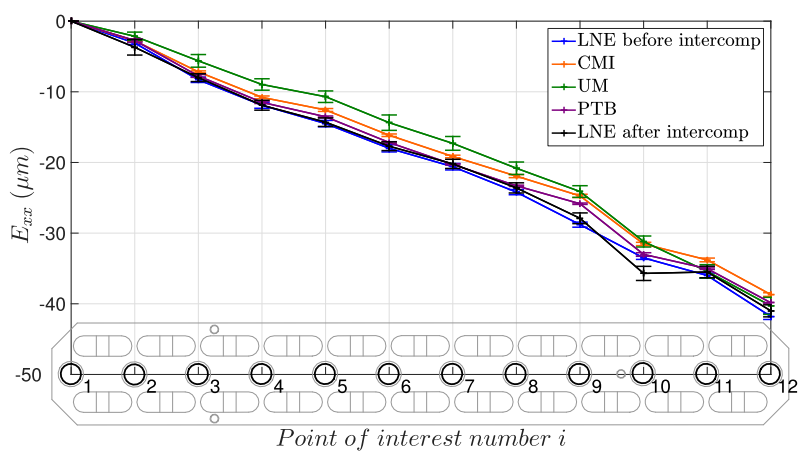

(a) Linear positioning error $E_{x x}^{j}\left(O_{i}\right)$.

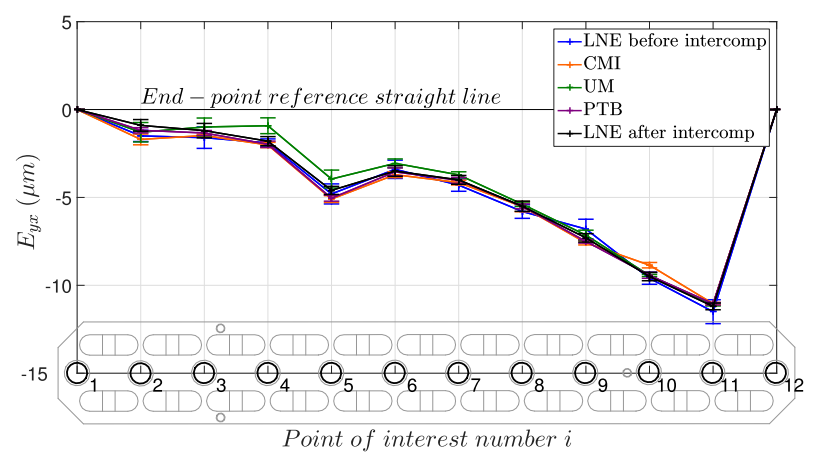

(b) Horizontal straightness error $E_{y x}^{j}\left(O_{i}\right)$.

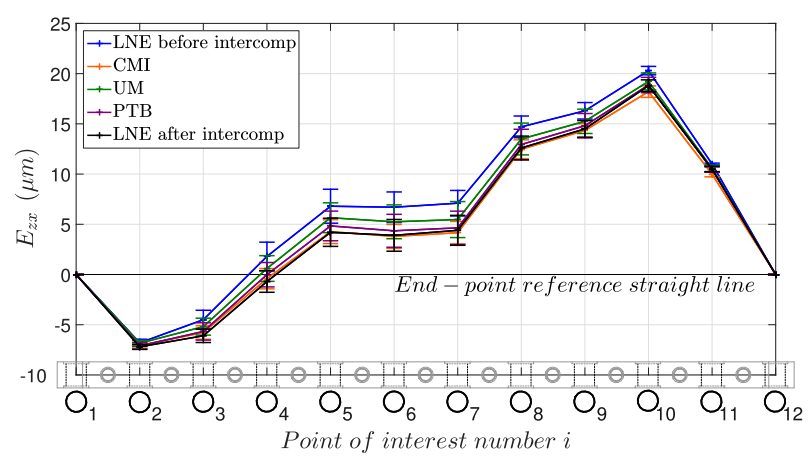

(c) Vertical straightness error $E_{z x}^{j}\left(O_{i}\right)$.

Fig. 9: Measurement results for each participant's measurements.

$$
\begin{array}{r}
\forall i \in \llbracket 1 ; 12 \rrbracket, j \in\{\text { LNE, CMI, UM, PTB, LNE }\} \\
\left\{\begin{array}{l}
U\left(d_{x x}^{j, k}\right)=k\left(u^{2}\left(E_{x x}^{j}\left(O_{i}\right)\right)+u^{2}\left(E_{x x}^{k}\left(O_{i}\right)\right)\right)^{\frac{1}{2}} \\
U\left(d_{y x}^{j, k}\right)=k\left(u^{2}\left(E_{y x}^{j}\left(O_{i}\right)\right)+u^{2}\left(E_{y x}^{k}\left(O_{i}\right)\right)\right)^{\frac{1}{2}} \\
U\left(d_{z x}^{j, k}\right)=k\left(u^{2}\left(E_{z x}^{j}\left(O_{i}\right)\right)+u^{2}\left(E_{z x}^{k}\left(O_{i}\right)\right)\right)^{\frac{1}{2}}
\end{array}\right.
\end{array}
$$

The degrees of equivalence are depicted in figure 12 .

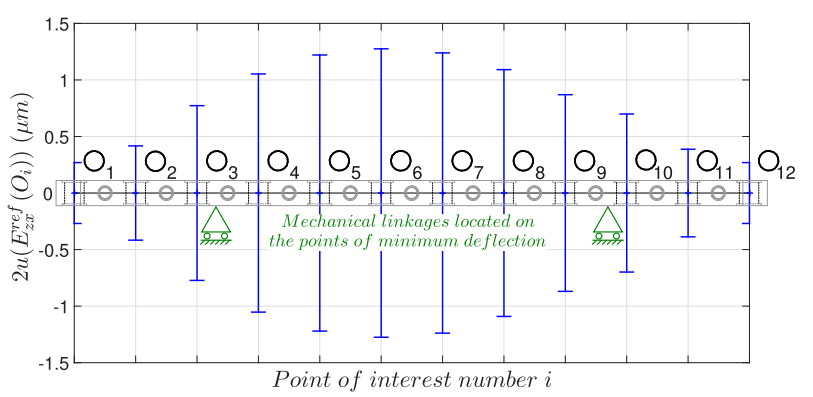

Fig. 10: Associated standard deviation $u\left(E_{z x}^{r e f}\left(O_{i}\right)\right)$ of the MFB.

\section{Discussion}

Tests were performed at four NMIs, with respect to the defined calibration procedure. Reversal and substitution techniques were applied in order to compensate the repeatable motion errors of used CMMs. Figure 8 illustrates the results obtained at LNE. A maximum value of deviation equal to $2.8 \mu \mathrm{m}$ can be observed in $E_{y x}^{L N E}\left(O_{6}\right)$ between both calibration tests (Figure 8b). This deviation can be considered smaller than the uncertainty of measurement, estimated for the LNE's CMM $\left(u_{C M M}\right)$. Nevertheless, this deviation could be explained by a deflection of the MFB between both first and last measurement at the LNE (i.e. during the intercomparison).

Figure 10 shows the evaluation of the standard uncertainty $u\left(E_{z x}^{r e f}\left(O_{i}\right)\right)$ associated with the reference value $E_{z x}^{r e f}\left(O_{i}\right)$ of the MFB. The adopted definition of RSL based on the end-points (Figure 10) could be considered as non-optimal to minimize the uncertainty of measurement, as the least squares RSL (Figure 13a) and mean minimum zone RSL (Figure 13b). In such case, the uncertainty of measurement becomes less than $1 \mu \mathrm{m}$. Nevertheless, whatever the measurement, either the calibration of the MFB or using it for machine calibration, this definition is rested on the actual geometry of the MFB and only one RSL is required for both straightness errors along horizontal and vertical axes of $R_{M F B}$. The standard uncertainties associated with the KCRVs could be minimized using another definition of RSL. Table 5 and figure 13 depict the impact of the RSL definition on the identified straightness errors and the associated standard uncertainty. The deviations between the standard uncertainties $u\left(E_{z x}^{r e f}\left(O_{i}\right)\right)$ observed in table 5 and figure 13 depend on the definition of the RSL. Both least square and mean minimum zone RSLs allow minimizing the standard uncertainty. The minimum standard uncertainty based on least-squares and mean minimum zone RSLs (Figure 13) are caused by 


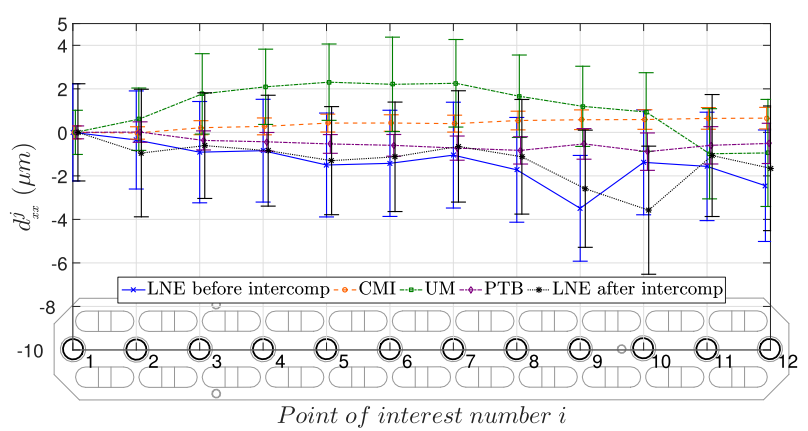

(a) Deviation $d_{x x}^{j}$ and associated uncertainty $U\left(d_{x x}^{j}\right)$ between each participant and the reference value of linear positioning error $E_{x x}^{r e f}\left(O_{i}\right)$.

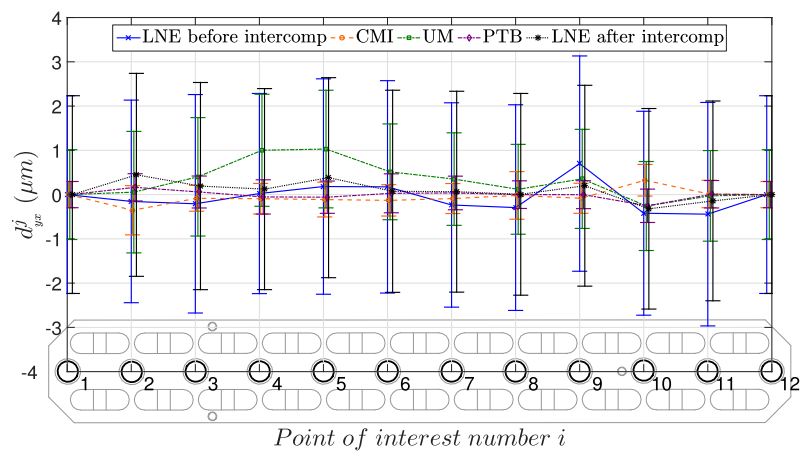

(b) Deviation $d_{y x}^{j}$ and associated uncertainty $U\left(d_{y x}^{j}\right)$ between each participant and the reference value of horizontal straightness error $E_{y x}^{r e f}\left(O_{i}\right)$.

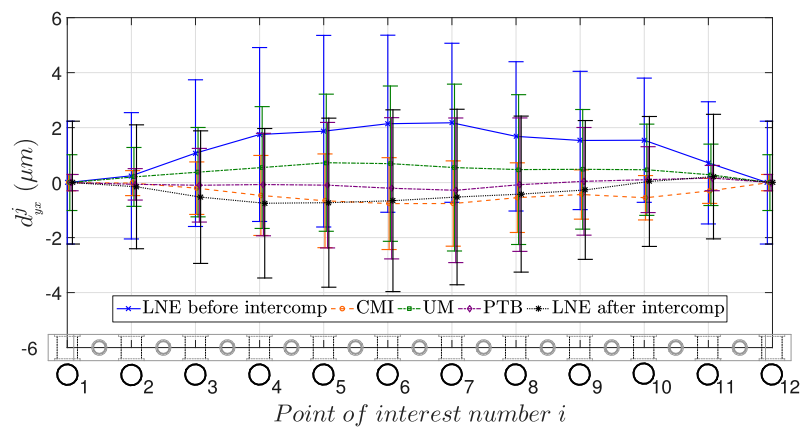

(c) Deviation $d^{j}$ and associated uncertainty $U\left(d^{j}\right)$ between each participant and the reference value of vertical straightness error $E_{z x}^{r e f}\left(O_{i}\right)$.

Fig. 11: Measurement results for each participant.

several sources of random errors such as environment, handling and tightening operations.

The figure 11 shows the degree of equivalence of measurements performed at each NMI to the group of key comparison participating NMIs. Deviations from the KCRV (figures 11) enable one to judge if there is a systematic shift in the results from a given NMI in relation to all the NMIs taken together, while the uncertainty in such deviation indicates the reproducibility

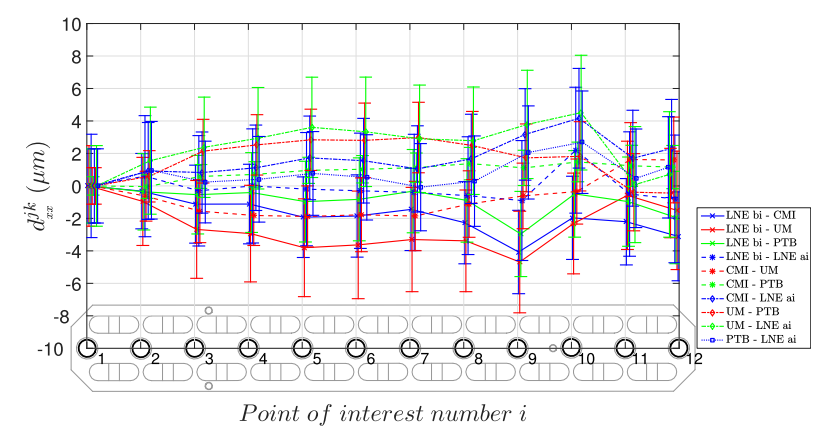

(a) Deviation $d_{x x}^{j k}$ and associated uncertainty $U\left(d_{x x}^{j k}\right)$ between participants $j$ and $k$.

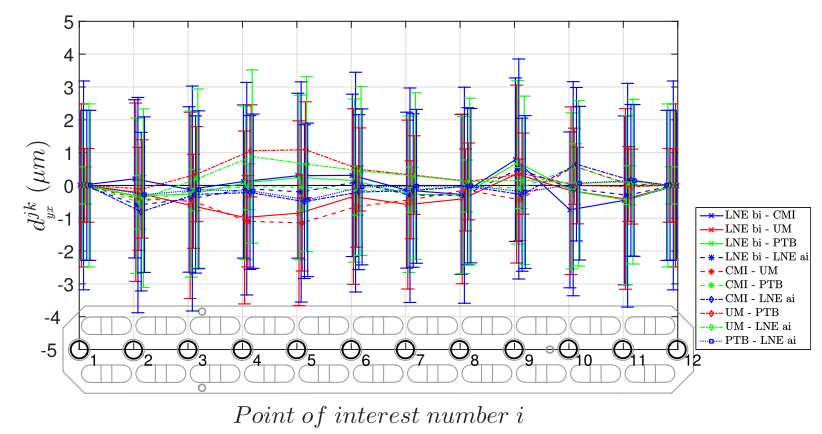

(b) Deviation $d_{y x}^{j k}$ and associated uncertainty $U\left(d_{y x}^{j k}\right)$ between participants $j$ and $k$.

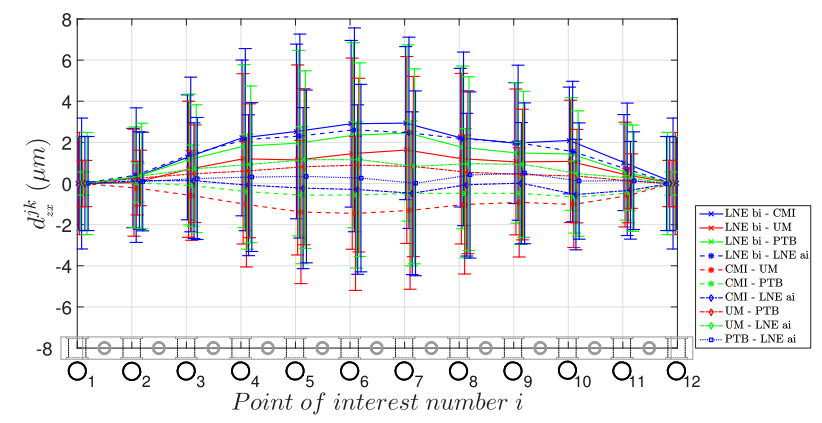

(c) Deviation $d_{z x}^{j k}$ and associated uncertainty $U\left(d_{z x}^{j k}\right)$ between participants $j$ and $k$.

Fig. 12: Degree of equivalence between participants $j$ and $k$.

within that NMIs. In the figure 11, no systematic errors are neglected and all pair differences between measurement results are within the uncertainty limits of their definition. Figure 11a and figure 11c summarize the deviations between one NMI in relation to all the NMIs taken together. The maximum values are equal to $-3.6 \mu \mathrm{m}$ and $2.1 \mu \mathrm{m}$ in figure 11a for $d_{x x}^{j}$, and in figure 11c for $d_{z x}^{j}$ respectively. Deviations are accentuated in the $12 \mathrm{a}$ and figure $12 \mathrm{c}$ which depict degrees of equivalence between two measurements results provided by two different NMIs. This degree of equivalence of one measured value with respect to the other is cal- 
culated as the difference between their respective deviations from the key comparison reference value. The maximum values are equal to $-4.7 \mu \mathrm{m}$ and $2.9 \mu \mathrm{m}$ respectively in figure 12a for $d_{x x}^{j k}$, and in figure 12c for $d_{z x}^{j k}$.

These deviations could be caused by the deflection of the MFB and affect the reproducibility of calibration. The 3 mechanical linkages of the MFB are located on the points of minimum deflection as calculated analytically and are not exactly identical to Airy points $[14,22]$. This precaution minimizes the defection of the MFB under its own weight about to $0.16 \mu \mathrm{m}$, without tightening operation. The effects of tightening operations during the calibration of the MFB has evaluated a posteriori with 50 tightening cycles. The results highlight an effect on the bending of the MFB equal to $-4.7 \pm 2.7 \mu \mathrm{m}$ and on the length of the MFB equal to $-3.7 \pm 2.7 \mu \mathrm{m}$. The bending could be reduced by the reversal technique during calibration contrary to the effect on the own length of the MFB. So the intercomparison reveal additional sources of error like deflection of the MFB, which could be minimized by improving of the clamping system.

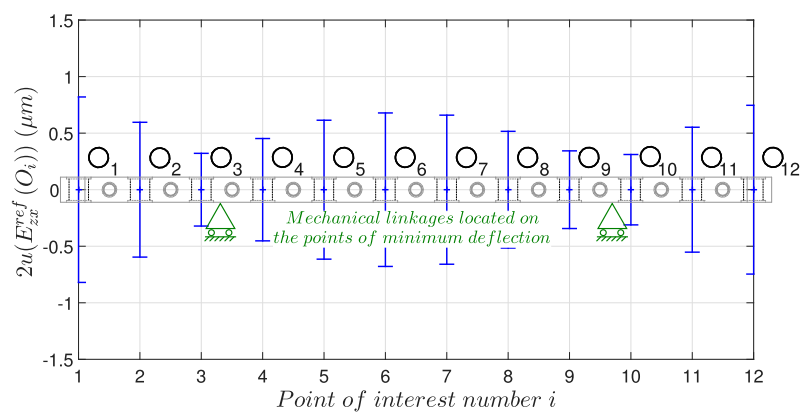

(a) Associated standard deviation $u\left(E_{z x}^{r e f}\left(O_{i}\right)\right)$ of the MFB based on least-squares RSL.

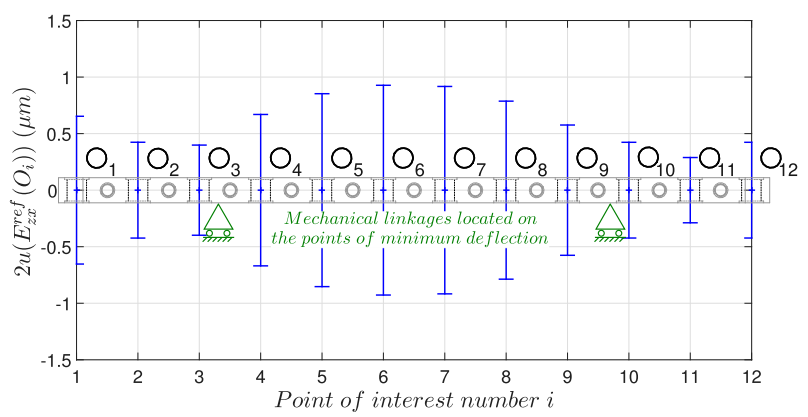

(b) Associated standard deviation $u\left(E_{z x}^{r e f}\left(O_{i}\right)\right)$ of the MFB based on mean minimum zone RSL.

Fig. 13: Associated standard deviations based on different definitions of RSL.

\section{Conclusion}

The design of the MFB involves several patterns, including cylindrical and planar geometric entities, useful to extract 12 points of interests and then providing 3 geometric errors (linear positioning error and 2 straightnesses) after calibration procedure. Calibration of the MFB was carried out when applying the reversal technique in order to separate the motion errors of the $\mathrm{CMM}$ and the true intrinsic parameters of the MFB. An intercomparison organised between European NMIs using the Multi-Feature Bar (MFB) confirm the reproducibility of calibration procedure and the long-lasting quality of the geometry. Each participant measured the thermo-invariant material standard using the same procedure. The intercomparison has provided consistency data and key comparison reference values. These results could be used for the compensation of intrinsic geometry of MFB during the identification of geometric errors on the CMMs or MTs. The adopted definitions of the straightness errors were based on the end-points RSL since it greatly simplified the identification of geometric errors on the machines (i.e. CMMs or MTs). However, the analysis of the intercomparison results brings us to the conclusion that the standard uncertainties associated with the KCRVs could be better managed using the least squares or mean minimum zone RSLs and by improving the clamping system and clamping operation. In any case, the end-user will be able to choose between the three definitions of RSLs.

Acknowledgements This work was funded through the European Metrology Research Programme (EMRP), project IND 62: JRP-TIM (Traceable In-process dimensional Measurement). The authors sincerely thank the EMRP organisation which is jointly funded by the EMRP participating countries within EURAMET and the European Union.

The authors warmly thank the partners of the JRP-TIM project for their contributions in this intercomparison, especially:

- Klaus Wendt, Christian Held and Norbert Gerwien at: Physikalisch-Technische Bundesanstalt (PTB), Germany,

- Vít Zelený and Pavel Skalník at:

Český Metrologický Institut (CMI), Czech Republic,

- Bojan Ačko and Mitja Mlakar at:

Univerza v Mariboru (UM), Slovenia.

The authors also sincerely thank the consortium of EMPIR Projet: 15SIB01-FreeFORM.also

\section{References}

1. G. Vailleau, Machine à mesurer tridimensionnelle et incertitude de mesure. analyse de l'intercomparaison. rapport final. (final report presented at seminar, 24-25 november 1992, nimes, france (in french). Tech. rep., Laboratoire National de Métrologie et d'Essais (1992) 
Table 5: Key comparison reference values of the MFB with different definitions of the reference straight line (RSL).

\begin{tabular}{|c|c|c|c|c|c|c|c|c|c|c|c|c|}
\hline \multirow{4}{*}{$O_{i}$} & \multicolumn{4}{|c|}{ End-point RSL } & \multicolumn{4}{|c|}{ Least squares RSL } & \multicolumn{4}{|c|}{ Mean minimum zone RSL } \\
\hline & \multicolumn{2}{|c|}{$E_{y x}^{r e f}\left(O_{i}\right)$} & \multicolumn{2}{|c|}{$E_{z x}^{r e f}\left(O_{i}\right)$} & \multicolumn{2}{|c|}{$E_{y x}^{r e f}\left(O_{i}\right)$} & \multicolumn{2}{|c|}{$E_{z x}^{r e f}\left(O_{i}\right)$} & \multicolumn{2}{|c|}{$E_{y x}^{r e f}\left(O_{i}\right)$} & \multicolumn{2}{|c|}{$E_{z x}^{r e f}\left(O_{i}\right)$} \\
\hline & values & $\mathbf{u}$ & values & $\mathbf{u}$ & values & $\mathbf{u}$ & values & $\mathbf{u}$ & values & $\mathbf{u}$ & values & $\mathbf{u}$ \\
\hline & $\mu m$ & $\mu m$ & $\mu m$ & $\mu m$ & $\mu m$ & $\mu m$ & $\mu m$ & $\mu m$ & $\mu m$ & $\mu m$ & $\mu m$ & $\mu m$ \\
\hline 1 & 0,0 & 0,3 & 0,0 & 0,3 & 0,9 & 0,3 & 3,3 & 0,8 & 5,5 & 0,3 & $-2,3$ & 0,7 \\
\hline 2 & $-1,4$ & 0,4 & $-7,0$ & 0,4 & 0,2 & 0,3 & $-5,2$ & 0,6 & 4,2 & 0,4 & $-10,0$ & 0,4 \\
\hline 3 & $-1,4$ & 0,3 & $-5,6$ & 0,8 & 0,7 & 0,3 & $-5,2$ & 0,3 & 4,1 & 0,3 & $-9,3$ & 0,4 \\
\hline 4 & $-1,9$ & 0,3 & 0,1 & 1,1 & 0,8 & 0,3 & $-1,1$ & 0,5 & 3,6 & 0,3 & $-4,5$ & 0,7 \\
\hline 5 & $-5,0$ & 0,3 & 5,0 & 1,2 & $-1,7$ & 0,3 & 2,2 & 0,6 & 0,5 & 0,3 & $-0,3$ & 0,9 \\
\hline 6 & $-3,6$ & 0,3 & 4,6 & 1,3 & 0,3 & 0,3 & 0,3 & 0,7 & 2,0 & 0,3 & $-1,4$ & 0,9 \\
\hline 7 & $-4,1$ & 0,3 & 5,0 & 1,2 & 0,5 & 0,3 & $-0,9$ & 0,7 & 1,5 & 0,3 & $-1,8$ & 0,9 \\
\hline 8 & $-5,5$ & 0,3 & 13,0 & 1,1 & $-0,4$ & 0,3 & 5,8 & 0,5 & 0,0 & 0,3 & 5,7 & 0,8 \\
\hline 9 & $-7,5$ & 0,3 & 14,7 & 0,9 & $-1,8$ & 0,3 & 6,2 & 0,3 & $-2,0$ & 0,3 & 6,8 & 0,6 \\
\hline 10 & $-9,2$ & 0,3 & 18,8 & 0,7 & $-2,9$ & 0,3 & 8,7 & 0,3 & $-3,7$ & 0,3 & 10,0 & 0,4 \\
\hline 11 & $-11,1$ & 0,3 & 10,3 & 0,4 & $-4,1$ & 0,3 & $-1,2$ & 0,6 & $-5,5$ & 0,3 & 0,9 & 0,3 \\
\hline 12 & 0,0 & 0,3 & 0,0 & 0,3 & 7,5 & 0,3 & $-13,0$ & 0,7 & 5,5 & 0,3 & $-10,0$ & 0,4 \\
\hline
\end{tabular}

2. H. Kunzmann, E. Trapet, F. Wäldele, CIRP Annals - Manufacturing Technology 44(1), 479 (1995). DOI http://dx.doi.org/10.1016/S0007-8506(07)62367-1. URL http://www.sciencedirect.com/science/article/pii/ S0007850607623671

3. H.N. Hansen, L.D. Chiffre, Precision Engineering 23(3), 185 (1999). DOI http://dx. doi.org/10.1016/S0141-6359(99)00009-4 URL http://www.sciencedirect.com/science/article/ pii/S0141635999000094

4. O. Jusko, J. Salsbury, H. Kunzmann, CIRP Annals - Manufacturing Technology 48(1), 413 (1999). DOI http://dx.doi.org/10.1016/S0007-8506(07)63215-6. URL http://www.sciencedirect.com/science/article/pii/ S0007850607632156

5. R. Thalmann, Metrologia 37(3), 253 (2000). URL http: //stacks. iop.org/0026-1394/37/i=3/a=12

6. S. Osawa, K. Busch, M. Franke, H. Schwenke, Precision Engineering 29(1), 56 (2005). DOI http://dx.doi.org/10.1016/j.precisioneng.2004.04.006. URL http://www.sciencedirect.com/science/ article/pii/S014163590400087X

7. T. Liebrich, B. Bringmann, W. Knapp, Precision Engineering 33(1), 1 (2009). DOI https://doi.org/10.1016/j.precisioneng.2008.02.003. URL http://wWw.sciencedirect.com/science/ article/pii/S0141635908000342

8. B. Ačko, M. McCarthy, F. Haertig, B. Buchmeister, Measurement science and technology 23(9), 094013 (2012). URL http://iopscience.iop.org/article/10. 1088/0957-0233/23/9/094013/meta

9. ISO 230-1:2012. Test code for machine tools - part 1: Geometric accuracy of machines operating under no-load or quasi-static conditions (2012)

10. R. Ramesh, M. Mannan, A. Poo, International Journal of Machine Tools and Manufacture 40(9), 1235 (2000). DOI http://dx.doi.org/10.1016/S0890-6955(00)00009-2. URL http://www.sciencedirect.com/science/article/pii/ S0890695500000092

11. ISO 230-7:2007. Test code for machine tools - part 7: Geometric accuracy of axes of rotation (2007)

12. H. Schwenke, W. Knapp, H. Haitjema, A. Weckenmann, R. Schmitt, F. Delbressine, CIRP Annals - Manufacturing Technology 57(2), 660 (2008). DOI 10.1016/j. cirp.2008.09.008. URL http://www.sciencedirect.com/ science/article/pii/S0007850608001960
13. Physikalisch-Technische Bundesanstalt (PTB). Emrp ind62: Jrp-tim (traceable in-process dimensional measurement) (2013). URL https://www.ptb.de/emrp/ ind62-home.html

14. F. Viprey, H. Nouira, S. Lavernhe, C. Tournier, Precision Engineering 46, 323 (2016). DOI http://dx.doi.org/10.1016/j.precisioneng.2016.06.002. URL http://www.sciencedirect.com/science/ article/pii/S0141635916300733

15. C.J. Evans, R.J. Hocken, W.T. Estler, CIRP Annals - Manufacturing Technology 45(2), 617 (1996). DOI http://dx.doi.org/10.1016/S0007-8506(07)60515-0. URL http://www.sciencedirect.com/science/article/pii/ S0007850607605150

16. JCGM 200:2012. International vocabulary of metrology - basic and general concepts and associated terms (VIM) - 3rd edition (2012). URL http://www.bipm.org/en/ publications/guides/vim.html

17. CIPM, Guidelines for CIPM key comparisons (Comité International des Poids et Mesures, 2003). URL http: //www.bipm.org/pdf/guidelines.pdf

18. H. Schwenke, M. Franke, J. Hannaford, H. Kunzmann, CIRP Annals - Manufacturing Technology 54(1), 475 (2005). DOI http://dx.doi.org/10.1016/S0007-8506(07) 60148-6. URL http://www.sciencedirect.com/ science/article/pii/S0007850607601486

19. JCGM 100:2008. Evaluation of measurement data - guide to the expression of uncertainty in measurement (2008). URL http://www.bipm.org/utils/common/ documents/jcgm/JCGM_100_2008_F.pdf

20. ISO 14253-2:2011. Geometrical product specifications (GPS) - inspection by measurement of workpieces and measuring equipment - part 2: Guidance for the estimation of uncertainty in gps measurement, in calibration of measuring equipment and in product verification (2011)

21. M.G. Cox, Metrologia 39(6), 589 (2002). URL http: //stacks. iop.org/0026-1394/39/i=6/a=10

22. F. Viprey, Modélisation et caractérisation des défauts de structure de machine-outil 5 axes pour la mesure inprocess. Phd manuscript in french, Université ParisSaclay (2016). URL https://tel.archives-ouvertes. fr/tel-01416209/ 